\title{
Linfoma de Hodgkin con depleción linfocítica e infiltración difusa de médula ósea
}

\author{
Hodgkin's lymphoma with lymphocyte depletion and diffuse bone
} marrow infiltration

\author{
Fernando Carballo ${ }^{1}$ Rubén López², Victor Mechán ${ }^{3}$, Luis Vilchez \\ ${ }^{1}$ Servicio de Medicina, Hospital Dos de Mayo, Lima, Perú \\ ${ }^{2}$ Jefe, Sala de Medicina San Pedro, Hospital Nacional Dos de Mayo, Lima, Perú \\ ${ }^{3}$ Servicio de Hematología Clínica, Hospital Nacional Dos de Mayo, Lima, Perú
}

\begin{abstract}
Resumen
Se presenta el caso clínico de un paciente varón de 38 años de edad, agricultor, natural de Lamas, San Martín (selva peruana), quien desde hacia 8 meses presentaba diarreas, fiebre intermitente, dolor abdominal, pérdida ponderal y anemia severa. Aunque lúcido, a su ingreso el paciente exhibía mal estado general, palidez y adenopatías generalizadas de menos de $0,5 \mathrm{~cm}$, hepatoesplenomegalia y matidez desplazable. La tomografía computarizada abdominal reveló hepatoesplenomegalia y múltiples adenopatías retroperitoneales, mesentéricas y otras. La biopsia de ganglio mostró células de Reed Sternberg, células mononucleares, eosinófilos y escasos linfocitos. La inmunohistoquímica ganglionar fue positiva para anticuerpos CD15 y CD30. La biopsia de hueso señaló fibrosis difusa, células mononucleares y marcada escasez de linfocitos. La hibridización in situ para EBV-virus de Epstein Barr fue positiva en las células neoplásicas.

Palabras clave: Linfoma de Hodgkin con depleción linfocítica, síndrome linfoproliferativo, células de Reed Sternberg, EBV-virus de Epstein Barr.

Abstract

We present the case of a 38 year-old male, farmer, born in Lamas, San Martin (Peruvian jungle), who for the past 8 months suffered of diarrhea, intermittent fever, abdominal pain, weight loss and severe anemia. On admission the patient was lucid and exhibited malaise, pallor and generalized lymphadenopathy (size less than $0.5 \mathrm{~cm}$ ) hepatosplenomegaly and abdominal displaceable dullness. Abdominal computed tomography showed hepatosplenomegaly and retroperitoneal, mesenteric and other adenopathies. Node biopsy revealed Reed-Sternberg cells, mononuclear cells, eosinophiles and scarce lymphocytes. Immunohistochemical node staining was positive for CD15 and CD30 antibodies. Bone biopsy showed diffuse fibrosis, mononuclear cells and scarcity of lymphocytes. In situ hybridization for EBV Epstein Barr virus was positive in neoplastic cells.
\end{abstract}

Key words: Hodgkin lymphoma with lymphocytic depletion, lymphoproliferative syndrome, Reed Sternberg cells, EBV Epstein-Barr virus.

An Fac med. 2011;72(2):137-40

\section{INTRODUCCIÓN}

El linfoma de Hodgkin con depleción linfocitaria (LHDL) es el subtipo menos frecuente -menos del $5 \%{ }^{(1)}$ - de los casos de linfoma de Hodgkin (LH). Típicamente, compromete ganglios periféricos y retroperitoneales, hígado, bazo y médula ósea, en más de $50 \%$ de los casos, asociándose a fiebre intermitente, sudoración nocturna y marcada pérdida de peso. Las estadísticas señalan cierta asociación preferencial en adultos mayores entre este subtipo y el sida.

Se presenta un caso clínico de un paciente con linfoma de Hodgkin con depleción linfocitaria; asimismo, se evalúa las características clínicas y de laboratorio de este subtipo de presentación poco frecuente. También se presenta la respuesta inicial al tratamiento quimioterápico; al respecto, algunos estudios dan un promedio de vida de 3 años para este subtipo histológico a partir del diagnóstico, mientras otros señalan la posibilidad de cura si es que se brinda un tratamiento oportuno y correcto ${ }^{(2)}$. Sobre la etiología de esta presentación de linfoma, se discute la presencia de virus de Epstein Barr como factor desencadenante en el paciente ${ }^{(3,4)}$. 


\section{CASO CLÍNICO}

Varón de 38 años, agricultor, natural y procedente de Lamas, Dpto. de San Martín, jungla peruana, relativamente bien de salud hasta hacía 8 meses, en que presentó diarreas líquidas 10 veces al día, con moco, sin sangre, malestar general y dolor abdominal tipo cólico, que cedía con antiespasmódicos. Hidratado en el hospital de Lamas, le detectaron Ascaris lumbricoides en heces, recibiendo tratamiento apropiado. Cuatro meses antes de la admisión tuvo nuevo episodio de diarreas, con moco y sin sangre, dolor abdominal y fiebre persistente. Le detectaron Uncinarias spp. en heces. Ante la persistencia de fiebre y teniendo aglutinaciones 0 y $\mathrm{H}$ en rango de $160 \mathrm{U}$, tuvo el diagnóstico de fiebre tifoidea, recibiendo cloranfenicol oral por 14 días, sin respuesta adecuada. Durante su internamiento, le detectaron hemoglobina $5,4 \mathrm{~g} /$ $\mathrm{dL}$, transfundiéndole tres paquetes de glóbulos rojos. Hacía 15 días se agregó dolor lumbar difuso, persistente, tipo hincada, y disnea a medianos esfuerzos (caminar dos cuadras). Catorce días antes de ingresar al Hospital Nacional Dos de Mayo (HNDM), el paciente presentó sudoración profusa y fiebre de $39,5^{\circ} \mathrm{C}$, que aparecía y desaparecía cada 96 horas. El examen de gota grue- sa y el mielocultivo fueron negativos. El paciente vivía en casa de material noble, con agua y desagüe, criaba perros y cuyes. Fue diagnosticado de litiasis renal, en 1998. Fumaba ocasionalmente y era alérgico a metamizol. No recibió vacunaciones durante su infancia. El padre sufría de diabetes mellitus tipo II y, la madre, hipertensión arterial y valvulopatía cardiaca.

Al examen físico mostraba mal estado general, con palidez marcada, lúcido, orientado en tiempo y espacio. Frecuencia cardiaca 100/min, frecuencia respiratoria $24 / \mathrm{min}$, presión arterial $100 / 50$, temperatura $39,1^{\circ} \mathrm{C}$, talla 1,67 $\mathrm{cm}$, peso $47 \mathrm{~kg}$ (hacía 1 año pesaba 65 $\mathrm{kg}$ ). El tejido celular subcutáneo estaba disminuido. Había múltiples adenopatías blandas, móviles, no sensibles a la presión ni adheridas a planos profundos, de menos de $0,5 \mathrm{~cm}$, en cuello, axilas, ingles; discreto edema de miembros inferiores, fóvea $(+)$. Tórax normal; aparato cardiovascular con ingurgitación yugular ++ , soplo mitral sistólico III/VI. El abdomen era blando, depresible, ligeramente distendido, no doloroso, matidez desplazable, el hígado a 5 $\mathrm{cm}$ debajo del reborde costal derecho, el bazo a $2 \mathrm{~cm}$ del reborde, no palpable. La puño percusión lumbar fue positiva en el lado derecho.
El 20/05/2008, el volumen corpuscular era $87,8 \mathrm{fL}$, hemoglobina corpuscular media 27,7 $\mu \mathrm{g} / \mathrm{dL}$, hemoglobina $5,2 \mathrm{~g} / \mathrm{dL}$, leucocitos $2790 / \mathrm{mL}$, segmentados $1953 / \mathrm{mL} 70 \%$, linfocitos 391/mL $14 \%$, monocitos vacuolados $391 / \mathrm{mL}$ $14 \%$, eosinófilos $56 / \mathrm{mL} 2 \%$, velocidad de sedimentación $140 \mathrm{~mm} / \mathrm{h}$, plaquetas 100 000/mL, prueba de Coombs directa negativa, proteínas totales $3,5 \mathrm{~g} /$ $\mathrm{dL}$, seroalbúminas $1,7 \mathrm{~g} / \mathrm{dL}$, tiempo de protrombina $22 " / 12$ ", tiempo de tromboplastina $88 " / 37$ ", urea $32 \mathrm{mg} / 100 \mathrm{~mL}$ (N: 20-40), creatinina $0,6 \mathrm{mg} / \mathrm{dL}$, sodio $138 \mathrm{mEq} / \mathrm{L}$, potasio $4,5 \mathrm{mEq} / \mathrm{L}$, cloro $106 \mathrm{mEq} / \mathrm{L}$, calcio $7,1 \mathrm{mg} / 100 \mathrm{~mL}$.

El 26/05/2009, la tomografía axial computarizada de abdomen total mostró gran hepatoesplenomegalia, con nódulos superficiales; múltiples adenopatías retroperitoneales, mesentéricas e ilíacas. Además, derrame pleural leve y atelectasia pasiva, bilateral. La ecografía abdominal total halló hepatopatía difusa.

El 30/05/2008, la biopsia de ganglio cervical diagnosticó linfoma de Hodgkin clásico, con depleción linfocítica. La inmunohistoquímica del ganglio cervical halló CD3 (-), CD15 (+/-), CD20(-), CD30 (+++), CD $45(-)$, antígeno de membrana especial-EMA (-), quinasa 1 del linfoma anaplásico-

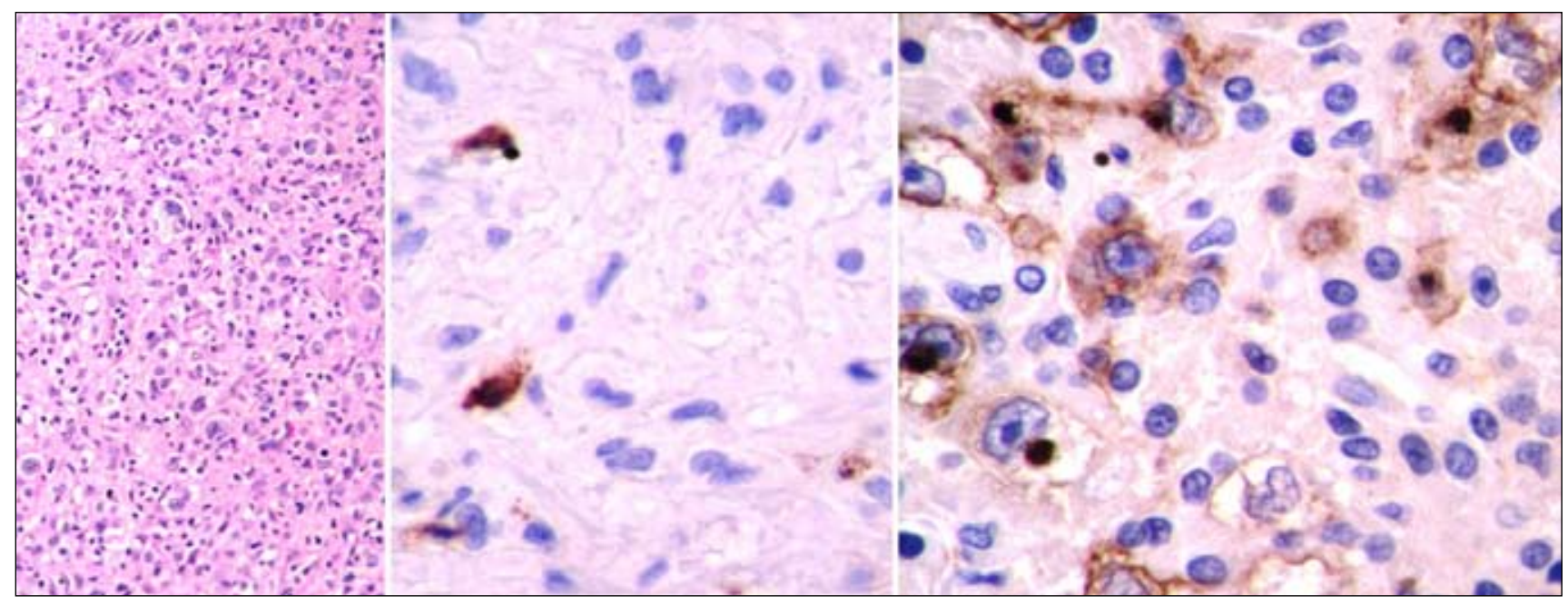

Figuras 1-3. Izquierda: Presencia de células mononucleares y de Reed Sternberg en biopsia de ganglio, H/E. Centro: Anticuerpos CD15 (+/-). Derecha: Anticuerpos CD30 (+++). 

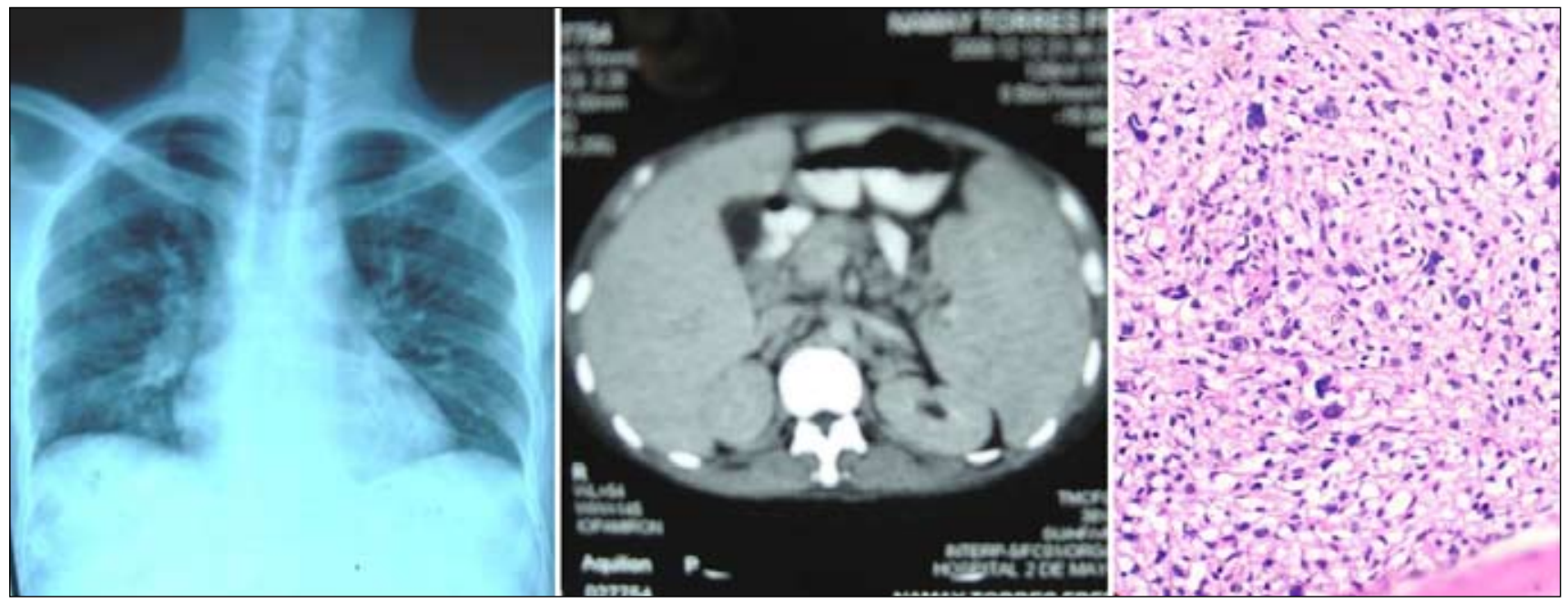

Figuras 4-6. Izquierda: Radiografía de tórax anteroposterior. Centro: Tomografía axial computarizada abdominal muestra hepatoesplenomegalia y múltiples ganglios retroperitoneales. Derecha: Biopsia de hueso señala infiltración celular y fibrosis difusa.

ALK-1 (-), fracción de crecimiento tisular-KI67 (>30\%), panqueratina $(-)$, antígeno común linfocitario-ACL (-). La biopsia de hueso fue informada como infiltración difusa por linfoma de Hodgkin clásico, subtipo depleción linfocítica; fibrosis difusa; presencia de células de Reed Sterberg. La hibridización in situ para EBV-virus de Epstein Barr en células neoplásicas fue positivo $(+++)$.

Inicialmente, el paciente recibió tres trasfusiones de glóbulos rojos y esquema adriamicina, vincristina, bleomicina, daunorubicina (AVBD); 5 días después, la fiebre desapareció y 20 días después los ganglios periféricos y la hepatoesplenomegalia habían desaparecido. Con un peso de 52 kilos, el paciente fue dado de alta, en razón de su relativo buen estado general. El día 31 posquimioterapia, el paciente exhibió una hemoglobina de 10,3 g/dL y hematocrito de $31 \%$. El paciente no regresó a la consulta externa.

\section{DISCUSIÓN}

El diagnóstico de linfoma de Hodgkin, subtipo depleción linfocítica (LHDL), se realizó en este paciente por las siguientes características: a) al identi- ficar células de Reed Sternberg (RS) en ganglio y hueso; b) al demostrar depleción de linfocitos en ganglio y hueso; y, c) por la presencia de signos, síntomas e inmunohistoquímica compatible ${ }^{(5,6)}$. Este subtipo poco frecuente representa menos del $5 \%$ de todos los subtipos de LH, siendo común en países en desarrollo. Clínicamente, tiende a comprometer hígado, bazo, médula ósea, ganglios linfáticos periféricos y retroperitoneales, cursando además con los clásicos signos B, como son fiebre y pérdida ponderal mayor al 10\% en los últimos 6 meses ${ }^{(7)}$.

Los resultados inmunohistoquímicos ganglionares de un panel de anticuerpos contra células RS y sus variantes fue reportado como CD15 (+) y CD30 $(+++)$, confirmatorios de $\mathrm{LH}^{(1,6)}$. $\mathrm{La}$ positividad para el virus de EpsteinBarr, mediante técnicas de hibridización en células neoplásicas, refrenda la asociación frecuente del virus con este subtipo de linfomas y su persistencia en ciertos medioambientes ${ }^{(1,7)}$.

Existen, no obstante, puntos de vista alternos. El LHDL podría en ciertos casos ser confundido por patólogos inexpertos, opinando algunos que, a la luz de nuevas herramientas diagnósticas, este subtipo podría desaparecer ${ }^{(1,2)}$. Así, ca- sos considerados anteriormente como linfoma de Hodgkin con depleción linfocítica (LHDL) son reconocidos hoy como linfoma difuso $\mathrm{B}$ de células grandes (LDBCG), linfoma de células grandes anaplásico (LCGA), LH variedad esclerosis nodular (LHEN), linfoma de Hodgkin clásico con depleción linfocítica (LHCDL), linfomas de células B de grado alto de malignidad, intermedios entre LDBCG y linfoma de Hodgkin clásico (linfomas de la zona gris) ${ }^{(6)}$. Según algunos investigadores, la inclusión de pacientes con formas agresivas de linfoma no Hodgkin (LNH) en el rubro de LHDL le ha dado a este subtipo una naturaleza más agresiva que la que le corresponde ${ }^{(7)}$. Curiosamente, todos los tumores mencionados anteriormente contenían células de Hodgkin-ReedSternberg (HRS), fibroblastos, histiocitos y escasos linfocitos ${ }^{(1,8)}$.

La incidencia general de células de RS en muestras de hueso oscila entre 2 y $29 \%{ }^{(9)}$, cantidades menores a las encontradas en biopsias de ganglio. Por tal razón, las biopsias de hueso aisladas (sin informes histológicos de biopsias de ganglio) no son suficientes para confirmar un diagnóstico de LH óseo. El diagnóstico de LH en hueso se da por seguro si previamente se ha identificado células de RS en el ganglio. El 
compromiso óseo por $\mathrm{LH}$ requiere, además de la presencia de células de RS, la existencia de variantes celulares mononucleares en un fondo compuesto por tejido conectivo fibroso conteniendo escasos linfocitos, eosinófilos, células plasmáticas e histiocitos ${ }^{(10)}$. Respecto a la fibrosis medular, presente en más de $50 \%$ de casos de LHDL, esta debe ser distinguida de otras causas de mielofibrosis ${ }^{(11,12)}$. Algunos asocian la presencia de fibrosis medular en LHDL a la posibilidad de recaídas tempranas y más efectos colaterales a consecuencia de la quimioterapia.

Aunque en este paciente no se realizó biopsia de hígado, la mejor explicación para la prolongación del TP y TTP y la hipoalbuminemia, en ausencia de compromiso cardiaco y renal, es la posible infiltración hepática por células neoplásicas ${ }^{(13)}$.

Respecto al pronóstico de vida del LHDL, algunos la estiman en 3 años y otros en menos de $20 \%$ a los 5 años, asociándola a pobre diferenciación de las células proliferantes. Un estudio clínico-patológico de 39 pacientes con LHDL confirmó la naturaleza agresiva de esta enfermedad, sin necesariamente tener un curso rápidamente fatal ${ }^{(2)}$; la supervivencia mediana en esta serie fue 25,1 meses, en tanto 8 pacientes (21\%) sobrevivieron más de 4 años; en dicha serie, hubo una incidencia alta de compromiso pulmonar contiguo (al igual que en nuestro paciente). Hoy en día se acepta que, a despecho del estadio avanzado de la enfermedad, los pacientes con LHDL pueden ser mejorados y hasta curados con quimioterapia ${ }^{(1,2,14)}$.

Aunque el paciente no continuó acudiendo a la consulta externa, no dejó de llamar la atención la adecuada y relativa buena respuesta al tratamiento quimioterápico inicial.

\section{REFERENCIAS BIBLIOGRÁFICAS}

1. Greer JP, Kinney MC, Cousar JB, Flexner JM, Dupont WD, Graber SE, Greco FA, Collins RD, Stein RS. Lymphocyte-depleted Hodgkin's disease. Clinicopathologic review of 25 patients. Am J Med. 1986;81(2):208-14

2. Bearman RM, Pangalis GA, Rappaport H. Hodgkin's disease, lymphocyte depletion type. A clinicopathologic study of 39 patients. Cancer J Clin. 1978;41(1):293-302.

3. Cohen JI. Epstein-Barr virus infection. NEJM. 2000;343(7):481-92.

4. Kusuda M, Toriyama K, Kamidigo NO, Itakura $\mathrm{H}$. A comparison of epidemiologic, histologic and virologic studies on Hodgkin's disease in Western Kenya and Nagasaki, Japan. Am J Trop Med Hyg. 1988;59(5):801-7.

5. Graham WS, Ferry JA, Hasserjian RP, Sohani AR, Longtine JA, Harris NL, Zukerberg LR. Lymphocyte depleted Hodgkin lymphoma: an evaluation with immunophenotyping and genetic analysis. Leuk Lymph. 2009;50(6):937-43.
6. Kant JA, Hubbard SM, Longo DL, Simon RM, De Vita Jr VT, Jaffe ES. The pathologic and clinical heterogeneity of lymphocyte-depleted Hodgkin's disease. J Clin Oncol. 1986;4:284-94.

7. Mesa JR, Espinosa E, Padrón CH, Losada R, Plasencia A, Hernández P. Enfermedad de Hodgkin: Nuevos conceptos clínico-patológicos. Rev Cub Hematol Inmunol Hemoter. 2000;16(1):21-9.

8. Karnik S, Srinivasan B, Nair S. Hodgkin's lymphoma: immunohistochemical features and its association with EBV LMP-1. Experience from a South Indian hospital. Pathol. 2003;35(3):207-11.

9. Kinney MC, Greer JP, Stein RS, Collins RD, Cousar JB. Lymphocyte-depletion Hodgkin's disease. Histopathologic diagnosis of marrow involvement. Am J Surg Pathol. 1986;10(3):219-26.

10. Kar R, Dutta S, Tyagi S. Clinically unsuspected Hodgkin's lymphoma diagnosed primarily from bone marrow trephine biopsy: Report of six cases. Indian J Pathol Microbiol. 2008;51:186-9.

11. Kabukçuoglu S, Öner Ü, Üstüner Z, Isiksoy S, Dündar $\mathrm{E}$, Tel N. Bone marrow involvement and myelofibrosis in Hodgkin's disease. Turk Trop J Med Sci. 1999;28:555-60.

12. Johnston PG, Sullivan FJ, Ruscetti FW, Longo DL, Connaghan DG. Transient reversal of bone marrow aplasia associated with lymphocyte depleted Hodgkin's disease after combination chemotherapy. Am J Hematol. 1991;38(1):34-60.

13. Dargent J-L, De Wolf-Peeters C. Liver involvement by lymphoma: Identification of a distinctive pattern of infiltration related to T-cell/histiocyte-rich B-cell lymphoma. Ann Diagn Pathol. 1998;2:363-9.

14. Schwartz RS. Hodgkin's disease-Time for a change. NEJM. 1997;337(7):494-6.

Trabajo recibido el 15 de noviembre de 2010 y aceptado para publicación el 13 de diciembre de 2010

Correspondencia:

Correo-e:fercarballo@hotmail.com 